\title{
Depression screening result among patients with the diabetic foot syndrome
}

\author{
Iryna Vlasenko' (PhD), Phylyp Prudyus² (PhD)
}

'Shupik National Medical Academy of Postgraduate Education, Kiev, Ukraine ?Vinnytsia Region Highly Specific Endocrinologic Center, Vinnytsia, Ukraine

\author{
vlasenkoiryna5@gmail.com
}

\section{Background}

The Diabetic Foot Syndrome (DFS) - widespread late complication of the Diabetes Mellitus (DM), which often (30$70 \%$ ) comes with foot trophic ulcer and can cause amputation (in $30-50 \%$ of the cases). The patients with DM have 15\% higher risk of the depression. Chronic diabetic complications associated with the high risk of the depression. The patient with the DM and the depression compensates the disease worse, it causes the increasing of the appearance of other chronic complications; also, it reduces quality of life and increases mortality. Likewise, the expences of the health care for the patient's treatment growing on $50-75 \%$.

In the IDF Guidance for the treatment of the people with type 2 DM evaluation of the patients' mental health is included. However, people with DM are poor diagnosed with the depression: $50-75 \%$ of the cases are not diagnosed. Consequently, patients with DM require active detection and treatment of the anxious disorder with depression symptoms, especially with such serious complication as DFS.

\section{Aim}

To evaluate popularity of the depressive and anxious syndromes among patients with DFS.

\section{Methodology}

Screening of the depressive disorders conducted among patients with DFS (including foot ulcer affect), who was hospitalized in the Department of Surgery in Vinnytsia Region Highly Specific Endocrinologic Center on 10.2016-03.2017. HADS (Hospital anxiety and depression scale) which was developed by A.S. Zigmond and R.P. Shraith was used according to the $\mathrm{WHO}$ recommendations. The scale includes 14 statements, which consists of two subscales: anxious (odd items) and depression (even items). Each statement has 4 answer's variants. Patient should have been choosing that variant, which was based on his/her condition last week. The summary of the result according to the HADS both subscales for each of them should be within 6-9 points, this showed to the subclinical demonstration of the anxiety and depression, 10 and more points demonstrated clinically apparent. Also, with the goal to detect the impact of the different medical and social factors on the level of the anxiety and depression, the next information was indicated: sex, age, duration and severity of $D M$, kind of blood glucose lowering drug (if insulin- the length of treatment), $\mathrm{HbA} 1 \mathrm{c}$ level. The results of the research were statistical processed.

\section{Results}

Survey of 92 patients with DM were done. Type $1 \mathrm{DM}$ had 11 patients (12\%), Type $2 \mathrm{DM}-80$ patients (88\%). Average age was $55,9 \pm 10,6$ years, $39 \%$ of which - men, women- $61 \%$, average level of $\mathrm{HbA} 1 \mathrm{c}-8,8 \% \pm 2,1$ (DM compensation supposed with the level of $\mathrm{HbA} 1 \mathrm{c}$ less than $7 \%$ ).

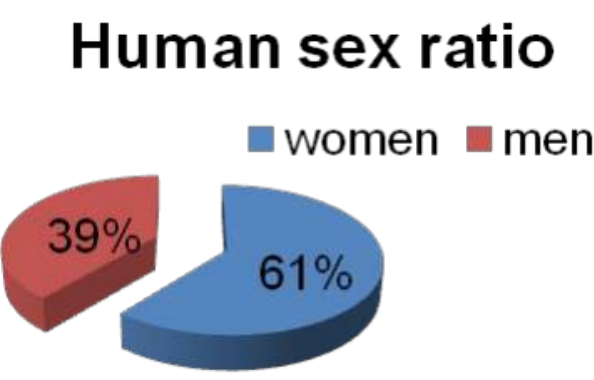

Type of Diabetes Melitus

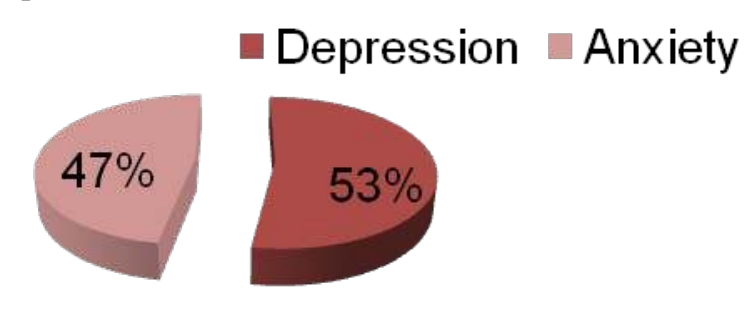

Depression of different seriousness were discovered for 40 patients $(42 \%)$. Anxiety were diagnosed for 36 patients (39\%), subclinical had 20 patients (22\%), clinical -16 patients $(17 \%)$. Herewith $82 \%$ of patients (33 from 40 ) with depression had anxiety (15- subclinical, 18- clinical). Anxious disorder with depression symptoms quite frequently happens in the group of Type 2 DM.

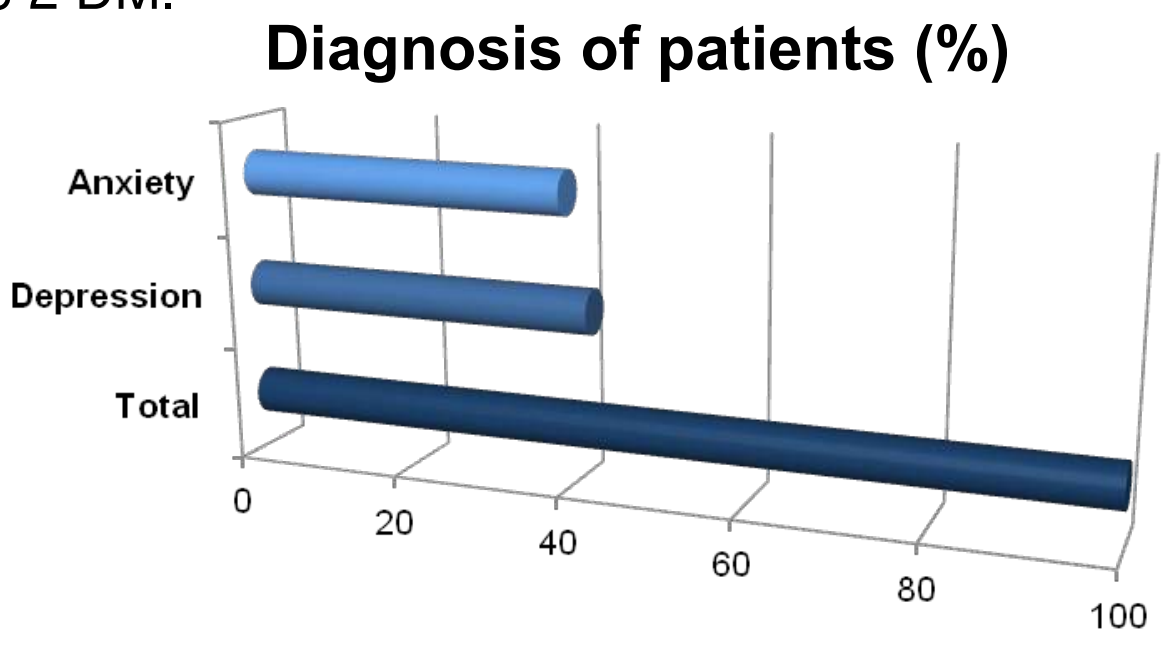

$88 \%$ of patients with the anxious disorder with depression symptoms with different seriousness, the level of $\mathrm{HbA1c}$ was higher then normal (7\%), it shows the deficiency of compensation of the disease and the high risk of appearance DM complications. The most elevated results according to the scale "anxiety" (12-15 points) had patients with severe DM (chronic injuries, ulcer relapses). Mixed anxious disorder with depression symptoms diagnosed for $80 \%$ of the patients among that people, who had insulin treatment. According to the quiz of patients with amputation it was discovered: before the surgery patients had fear and panic, but after the postoperative period there were moments, connected with sharp changes of outside world (isolation, limitation). It was established, if the disease is more than 5 years long, there is decrement in acuty of emotions. That is why very often there is a need at least behavioural therapy.

\section{Conclusions}

Anxious disorder with depression symptoms happens in $42 \%$ of the cases and more often happens with the people with Type 2 DM. Most of the people with anxious disorder with depression symptoms have no compensation of the DM, this causes the high risk of the appearance of the severe complications, reduces quality of life, cost escalation of the expenses of the health care. The research results show the necessity of not only medical but psychological aid for the patients with DFS.

\section{Key words:}

diabetes mellitus, anxious syndromes, depressive, diabetic foot syndrome (DFS),

1. Key Factors in Treating a Diabetic Wound. http://www.advancedtissue.com/6-key-factors-in-treating-a-diabetic-wound

2. Mezuk B, Eaton WW, Albrecht S, Golden SH. Depression and type 2 diabetes over the lifespan: a meta-analysis/ Diabetes Care. 2008 Dec;31(12):2383-90.

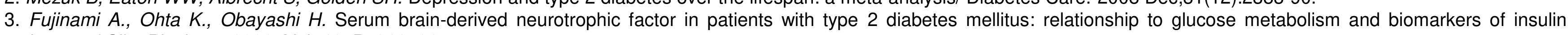
resistance / Clin. Biochem. 2008. Vol. 41. P. 812-817.

4. Castrén E., Rantamäki T. Role of brainderived neurotrophic factor in the aetiology of depression: implications for pharmacological treatment / CNS Drugs. 2010. Vol. 24. P. 1-7.

5. Van Dooren F. E. P., Nefs G., Schram M. T., Verhey F. R. J., Denollet J., Pouwer F. Depression and Risk of Mortality in People with Diabetes Mellitus: A Systematic Review and MetaAnalysis / Plos One. 2013. Vol. 8. Issue 3. 